\title{
Overexpression of CREB in the Nucleus Accumbens Shell Increases Cocaine Reinforcement in Self-Administering Rats
}

\author{
Erin B. Larson, ${ }^{1}$ Danielle L. Graham, ${ }^{1}$ Rose R. Arzaga, ${ }^{1}$ Nicole Buzin, ${ }^{1}$ Joseph Webb, ${ }^{1,2}$ Thomas A. Green, ${ }^{3}$ \\ Caroline E. Bass, ${ }^{4}$ Rachael L. Neve, ${ }^{5}$ Ernest F. Terwilliger, ${ }^{6}$ Eric J. Nestler, ${ }^{7}$ and David W. Self ${ }^{1}$ \\ ${ }^{1}$ Department of Psychiatry, University of Texas Southwestern Medical Center, Dallas, Texas 75390, ${ }^{2}$ Department of Neuroscience, St. Lawrence University, \\ Canton, New York 13617, ${ }^{3}$ Department of Pharmacology and Toxicology, University of Texas Medical Branch, Galveston, Texas 77550, ${ }^{4}$ Department of \\ Physiology and Pharmacology, Wake Forest University, Winston-Salem, North Carolina 27157, ${ }^{5}$ Department of Brain and Cognitive Sciences, \\ Massachusetts Institute of Technology, Cambridge, Massachusetts 02139, ${ }^{6}$ Department of Medicine, Beth Israel Deaconess Medical Center, Boston, \\ Massachusetts 02215, and 7Department of Neuroscience and Friedman Brain Institute, Mount Sinai School of Medicine, New York, New York 10029
}

Chronic exposure to addictive drugs enhances cAMP response element binding protein (CREB)-regulated gene expression in nucleus accumbens (NAc), and these effects are thought to reduce the positive hedonic effects of passive cocaine administration. Here, we used viral-mediated gene transfer to produce short- and long-term regulation of CREB activity in NAc shell of rats engaging in volitional cocaine self-administration. Increasing CREB expression in NAc shell markedly enhanced cocaine reinforcement of self-administration behavior, as indicated by leftward (long-term) and upward (short-term) shifts in fixed ratio dose-response curves. CREB also increased the effort exerted by rats to obtain cocaine on more demanding progressive ratio schedules, an effect highly correlated with viral-induced modulation of BDNF protein in the NAc shell. CREB enhanced cocaine reinforcement when expressed either throughout acquisition of self-administration or when expression was limited to postacquisition tests, indicating a direct effect of CREB independent of reinforcement-related learning. Downregulating endogenous CREB in NAc shell by expressing a short hairpin RNA reduced cocaine reinforcement in similar tests, while overexpression of a dominant-negative $\mathrm{CREB}^{\mathrm{S133 \textrm {A }}}$ mutant had no significant effect on cocaine self-administration. Finally, increasing CREB expression after withdrawal from selfadministration enhanced cocaine-primed relapse, while reducing CREB levels facilitated extinction of cocaine seeking, but neither altered relapse induced by cocaine cues or footshock stress. Together, these findings indicate that CREB activity in NAc shell increases the motivation for cocaine during active self-administration or after withdrawal from cocaine. Our results also highlight that volitional and passive drug administration can lead to substantially different behavioral outcomes.

\section{Introduction}

Addiction is a multifaceted disorder thought to arise from druginduced neuroadaptations in mesocorticolimbic systems regulating motivated behavior. Chronic drug exposure increases activity of the transcription factor cAMP response element binding protein (CREB) in the nucleus accumbens (NAc), a brain region involved in the motivational effects of drugs of abuse (Nestler, 2004). Increased NAc CREB activity is found after chronic cocaine or amphetamine administration (Shaw-Lutchman et al., 2003; Mattson et al., 2005), opiate withdrawal (Shaw-Lutchman et al., 2002; Chartoff et al., 2003), exposure to stress (Pliakas et al., 2001), and upon reexposure to cocaine-associated environmental contexts (Tropea et al., 2008). CREB activation in the NAc can occur through a variety of convergent intracellular signaling path-

\footnotetext{
Received June 16, 2011; revised Sept. 13, 2011; accepted Sept. 28, 2011.

Author contributions: E.B.L., D.L.G., E.N., and D.S. designed research; E.B.L., D.L.G., R.R.A., N.B., J.W., T.A.G., and C.E.B. performed research; T.A.G., C.E.B., R.L.N., E.F.T., and E.J.N. contributed unpublished reagents/analytic tools; E.B.L., D.L.G., and D.S. analyzed data; E.B.L. and D.W.S. wrote the paper.

We thank United States Public Health Service Grants DA010460, DA018743, DA024763, and DA008227 for supporting this research.

Correspondence should be addressed to David W. Self, Department of Psychiatry, University of Texas Southwestern Medical Center, 5323 Harry Hines Boulevard, Dallas, TX 75390-9070. E-mail: david.self@utsouthwestern.edu.

DOI:10.1523/JNEUROSCI.3070-11.2011

Copyright $\odot 2011$ the authors $\quad 0270-6474 / 11 / 3116447-11 \$ 15.00 / 0$
}

ways, many of which are implicated in addiction (McPherson and Lawrence, 2007). CREB is essential for cocaine-dependent alterations in gene expression (McClung and Nestler, 2003; Lemberger et al., 2008; Renthal et al., 2009), and alterations of NAc CREB activity can modulate a variety of processes, including neuronal excitability (Dong et al., 2006; Huang et al., 2008), natural and drug reward (Carlezon et al., 1998; Barrot et al., 2002), emotional affect (Pliakas et al., 2001; Barrot et al., 2002), sensorimotor gating (Berger et al., 2011), and reward-related learning and memory (Miller and Marshall, 2005; Kuo et al., 2007; Shiflett et al., 2009).

Striatal overexpression of CREB reduces locomotor sensitization to cocaine (Sakai et al., 2002), while localized CREB expression in the NAc shell attenuates cocaine-conditioned place preference (CPP), thereby revealing a conditioned aversion to cocaine (Carlezon et al., 1998; Pliakas et al., 2001). In contrast, brainwide loss of CREB in $\mathrm{CREB}^{\alpha \Delta}$ knock-out mice enhances CPP and the development of locomotor sensitization with repeated cocaine injections (Walters and Blendy, 2001), but also blocks stress-induced potentiation and reinstatement of cocaine CPP (Kreibich and Blendy, 2004; Kreibich et al., 2009). Localized overexpression of a dominant-negative CREB mutant $\left(\mathrm{mCREB}^{\mathrm{S133 \textrm {A }}}\right)$ in the NAc shell enhances cocaine-mediated CPP (Carlezon et al., 1998) and cocaine-mediated facilitation of brain stimulation reward (Dinieri et al., 2009). These findings have led to hypotheses that CREB mediates 
tolerance to cocaine's positive hedonic effects (Nestler and Malenka, 2004) but also increases responsiveness to stress (Kreibich and Blendy, 2004; Kreibich et al. 2009) and may mediate the negative or dysphoric aspects associated with withdrawal from cocaine use (Pliakas et al., 2001; Carlezon et al., 2005).

While several studies suggest that NAc CREB activity opposes cocaine effects, we reported that a transient antisense-induced reduction in NAc CREB levels reduces cocaine reinforcement of self-administration behavior (Choi et al., 2006), suggesting that upregulated CREB activity may actually increase rather than decrease cocaine reinforcement. In this study, we examined the effects of localized modulation of CREB in the NAc shell on cocaine self-administration behavior using short-acting (herpes simplex virus, HSV) and long-acting (adeno-associated virus, $\mathrm{AAV}$ ) viral vectors. We also compared the effects of CREB on cocaine self-administration behavior with its ability to modulate local expression of brain-derived neurotrophic factor (BDNF), since both CREB and BDNF in the NAc shell enhance cocaine reinforcement of self-administration behavior (Graham et al., 2007).

\section{Materials and Methods}

Animals. Adult male Sprague Dawley rats (Charles River Laboratories) initially weighing 250-300 g were individually housed in hanging wire cages in a climate-controlled environment $\left(21^{\circ} \mathrm{C}\right)$ on a $12 \mathrm{~h}$ light-dark cycle (lights on at 6:00 A.M.). All rats were habituated to the housing environment for at least $5 \mathrm{~d}$ before use in experiments. Rats were given food and water ad libitum, except during operant training with sucrose pellets. All experiments were conducted in accordance with the National Institutes of Health Guide for the Care and Use of Laboratory Animals and were approved by the University of Texas Southwestern Medical Center Institutional Animal Care and Use Committee (Dallas, TX).

Plasmid construction. Packaging and purification of a set of adenoassociated virus serotype 2 (AAV2) vectors constructed to deliver either green fluorescent protein (GFP), CREB, or mutant CREB ${ }^{\text {S133A }}$ (mCREB) was performed as described previously (Berger et al., 2011). GFP was fused to the N-terminal of both CREB and MCREB, and the constructs were inserted into a pAAV-MCS plasmid containing a cytomegalovirus (CMV) promoter. The CREB-GFP fusion protein has been shown to function similarly as wild-type CREB in reporter mice (Wallace et al., 2009). Expression of the AAV viruses is chronic and persistent, with peak transgene expression occurring by $7-10 \mathrm{~d}$ postinfusion, and elevated expression levels last for at least 1-2 months (Wallace et al., 2009; Sun et al., 2010; Berger et al., 2011). A bicistronic herpes simplex viral vector, HSV, was used to construct the HSV-GFP, HSV-CREB, and HSVmCREB viruses as described previously (Neve et al., 1997). GFP, CREB, or mCREB ${ }^{\text {S133A }}$ cDNA was inserted into an HSV-PrpUC amplicon and packaged using $5 \mathrm{dll} 1.2$ helper virus. Viruses were purified on a $10 \%$ sucrose gradient. In contrast to AAV, expression of the HSV viruses is transient, peaking at 2-3 d postinfusion and returning to baseline levels by $5-10 \mathrm{~d}$ postinfusion (Carlezon et al., 1998; Barrot et al., 2002).

For the AAV-scr-RNAi and AAV-CREB-RNAi viral vectors, cloning of interference RNA (RNAi) directed against CREB into an AAV2 vector plasmid was performed as described previously (Green et al., 2010). The CREB and scrambled (scr) control RNAi plasmids consisted of a CMV promoter flanked by AAV2 inverted terminal repeats, the sequence for enhanced GFP, and a simian virus 40-derived intron and polyadenylation signal (CMV-GFP). This was followed downstream by a murine U6 polymerase III promoter and synthetic oligonucleotides encoding short hairpin RNA (shRNA) for either CREB or scrambled control. For CREBRNAi, the shRNA targeted two different CREB mRNA sequences ( $5^{\prime}$ GAGCAATACAGCTGGCTAACA- $3^{\prime}$ and 5'-GCACTTAAGGACCTTT ACT $-3^{\prime}$ ), while the sequence for the scr control did not correspond to any known mRNA in the rat. The vectors were then packaged into AAV10 capsids using a hybrid packaging plasmid encoding AAV10 capsid functions as well as AAV2 replicase, enabling recognition of the AAV2 terminal repeats on the vector plasmids. The AAV2/10 pseudotyped virus was packaged using a standard triple transfection protocol of AAV2/10 and
AAV-shRNA vector plasmids and pHelper plasmid (Stratagene) into AAV-293 cells using calcium phosphate precipitation and later purified as described previously (Green et al., 2010).

Immunohistochemistry. Rats were given acute bilateral infusions of HSV or AAV viral vectors into the NAc shell $(+1.7 \mathrm{~mm}$ anterior to bregma, \pm 0.8 $\mathrm{mm}$ lateral, $-6.7 \mathrm{~mm}$ ventral to dura). At a time when viral overexpression was maximal (i.e., $3 \mathrm{~d}$ or 1 month postinfusion for HSV and AAV, respectively), rats were deeply anesthetized with chloral hydrate (400 mg/kg, i.p.) and perfused with $1 \times$ PBS followed by $4 \%$ paraformaldehyde. The brains were removed and stored in $4 \%$ paraformaldehyde overnight at $4^{\circ} \mathrm{C}$, followed by cryoprotection in $30 \%$ sucrose in $1 \times$ PBS. A microtome was used to cut $40 \mu \mathrm{m}$ coronal sections, which were stored free floating in $1 \times$ PBS with $0.01 \%$ sodium azide. Sections were blocked with $3 \%$ normal donkey serum and $0.3 \%$ Triton X-100 in $1 \times$ PBS for $2 \mathrm{~h}$ before incubation with chicken polyclonal anti-GFP (1:4000, Aves Labs) and rabbit monoclonal anti-CREB (1:1000; Cell Signaling Technology) in 3\% normal donkey serum and $0.3 \%$ Triton X-100 for $18-22 \mathrm{~h}$. After washing with $1 \times$ PBS, sections were incubated with fluorescein-tagged goat anti-chicken secondary antibody for GFP (1:250; Aves Labs) and Cy3-conjugated donkey anti-rabbit secondary antibody for CREB (1:200, Jackson ImmunoResearch Laboratories) for $2 \mathrm{~h}$.

Western blotting. To quantify the functionality of the AAV and HSV viruses, rats were given acute bilateral infusions of HSV or AAV viral vectors into the NAc shell as described above. An additional group of cannulated rats received two separate HSV infusions $17 \mathrm{~d}$ apart, and tissue was collected $3 \mathrm{~d}$ after the second HSV infusion to determine whether viral-induced BDNF regulation occurred after the second infusion for comparison with behavioral tests. Animals were anesthetized, decapitated, brains were dissected, and tissue punches (16 gauge) were taken from both the injected shell region and the adjacent core in $0.8 \mathrm{~mm}$ coronal sections. Tissue homogenates were processed by Western blot for the downstream CREB target BDNF (1:250; Santa Cruz Biotechnology) as described previously (Graham et al., 2007). $\beta$-Tubulin (1:200,000; Millipore) was used as a loading control to normalize BDNF values.

Sucrose pellet training. Rats were initially allowed to lever press for 45 mg sucrose pellets (BioServe) under restricted feeding conditions $(\sim 10-$ $15 \%$ reduction body weight) to facilitate the subsequent acquisition of cocaine self-administration. Rats were allowed to perform a single lever press to receive sucrose pellets until they self-administered 100 pellets per session for three consecutive sessions. The few rats that showed slower learning (e.g., did not reach 100 pellets on the first day) were then counterbalanced across groups to eliminate potential confounds due to inherent differences in operant learning. After acquisition, rats were free fed for at least $1 \mathrm{~d}$ before surgery.

Intravenous catheterization and intracranial cannulation/infusion. Before surgery, rats were given atropine $(0.15 \mathrm{cc} / \mathrm{rat}$, s.c. $)$ to aid in respiration, anesthetized with either Nembutal $(50 \mathrm{mg} / \mathrm{kg}$, i.p.) or a ketamine/ xylazine mixture (100 and $10 \mathrm{mg} / \mathrm{kg}$, i.p), and implanted with a chronic, in-dwelling silastic catheter in the right jugular vein as described previously (Edwards et al., 2007). After catheter implantation, rats were given either acute intracranial infusions of AAV viruses using a $5 \mu$ l Hamilton syringe with a 30 gauge injector tip or were implanted with a chronically indwelling 26 gauge bilateral intracranial guide cannula for subsequent HSV infusions (or AAV for extinction/reinstatement experiments). Acute AAV infusions were targeted directly into the medial NAc shell $(+1.7 \mathrm{~mm}$ anterior to bregma, $\pm 0.8 \mathrm{~mm}$ lateral, $-6.7 \mathrm{~mm}$ ventral to dura), while chronic indwelling bilateral guide cannulae were implanted $1.0 \mathrm{~mm}$ above the target region $(-5.7 \mathrm{~mm}$ ventral to dura). Chronic bilateral cannulae (Plastics One) were secured to the skull with machine screws and dental acrylic, and dummy cannulae (33-gauge) were placed into the guide cannula until the appropriate infusion time point. Viral vector infusions through chronic cannulae were performed by inserting specialized injectors (Plastics One) that extended $1.0 \mathrm{~mm}$ beyond the end of the guide cannula tip. All viruses were infused at a rate of $0.1 \mu \mathrm{l} / \mathrm{side} / 30$ $\mathrm{s}$, and injectors were held in place for an additional $2 \mathrm{~min}$ to allow for local diffusion into the NAc shell before injector removal. The total volume of virus injected was $1.0 \mu \mathrm{l} /$ side for AAV-GFP, AAV-CREB, and AAV-mCREB viruses, $2.0 \mu \mathrm{l} /$ side for HSV-GFP, HSV-CREB, and HSVmCREB viruses, and $0.5 \mu \mathrm{l} /$ side for the AAV-scr-RNAi and AAV-CREB- 
A
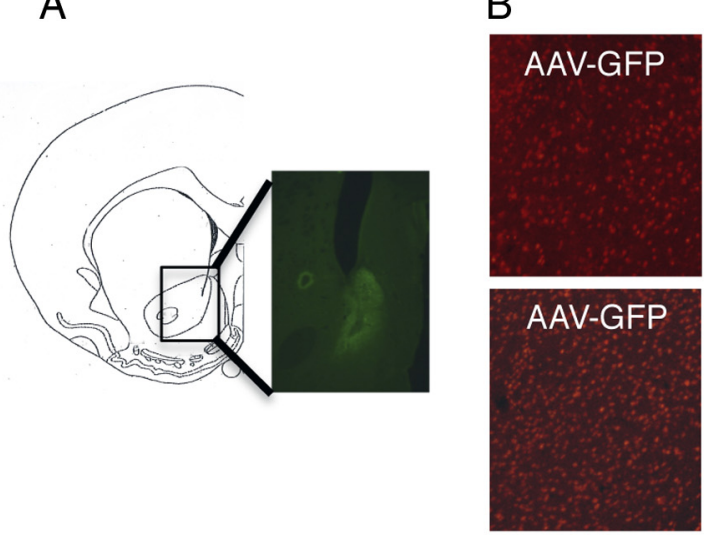
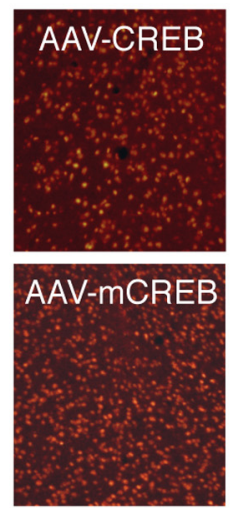

C
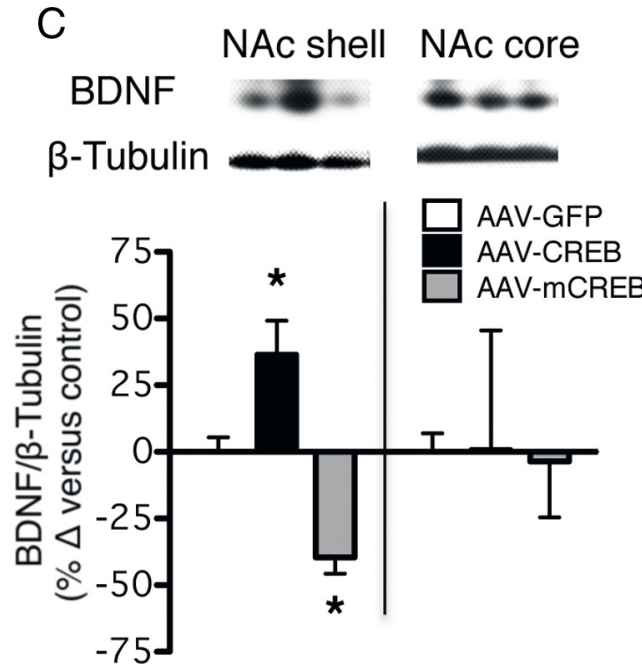

D AAV

until cocaine intake stabilized ( $<15 \%$ variability in intake over three consecutive sessions), and the FR requirement was increased from FR1 to FR3, and then to FR5 until intake again stabilized. The within-session dose-response testing began with a 30 min loading phase with access to the maintenance cocaine dose $(0.5 \mathrm{mg} / \mathrm{kg} /$ injection $)$. Rats were then allowed to self-administer one of five cocaine injection doses $(1.0,0.3,0.1,0.03$, and 0 $\mathrm{mg} / \mathrm{kg}$, i.v.) that were presented each hour in descending dose order. Dose-response testing was conducted over 1 week (6 d/week) in AAVinfused animals, and sessions 3 and 4 were averaged for data analysis. For HSV infusions, rats were tested for 1 week before HSV infusions, followed by 1 week during transient HSV-mediated overexpression and for an additional week postHSV when CREB overexpression declines to undetectable levels (Barrot et al., 2002). For data analysis, data were averaged across 2 d before HSV, days 3-4 after HSV infusion during overexpression, and days 3-4 during the week of postexpression.

Cocaine self-administration on a progressive ratio schedule of reinforcement. Following doseresponse testing on the FR5 schedule, rats selfadministered the maintenance dose of cocaine in daily $4 \mathrm{~h}$ sessions until cocaine intake stabilized. After stabilization, rats self-administered cocaine on a progressive ratio schedule in which each successive cocaine injection required an increasing amount of lever-press responses according to the following progression, $1,2,4,6,9,12$, 15,20 , etc., as described previously (Richardson and Roberts, 1996). Breakpoints were determined as the final ratio of responses/injection achieved before a $1 \mathrm{~h}$ period when no further injections were earned. Progressive ratio testing was conducted for two consecutive days at each dose $(0.25$ and $0.75 \mathrm{mg} / \mathrm{kg} /$ injection $)$ in counterbalanced order.

Extinction and reinstatement of cocaine seeking after cocaine withdrawal. In separate study groups, rats with intra-NAc shell cannula selfadministered cocaine $(0.5 \mathrm{mg} / \mathrm{kg}$, i.v. $)$ in daily

RNAi viruses. These infusion volumes led to similar infection areas in the NAc shell and did not diffuse into the adjacent NAc core region (Figs. $1 \mathrm{~A}$, $3 A$, and $5 A$ ). Following surgery, rats were given penicillin (60,000 IU/ 0.2 $\mathrm{ml}$, s.c.) to prevent infection, and ketoprofen analgesia was provided ( 5 $\mathrm{mg} / \mathrm{kg}$, s.c, $2 \times / \mathrm{d}$ for $3 \mathrm{~d}$ ). To prevent blood clotting and infection, catheters were flushed daily with heparinized saline $(20 \mathrm{IU} / \mathrm{ml})$ containing gentamicin sulfate $(0.33 \mathrm{mg} / \mathrm{ml})$, and triple antibiotic ointment was also applied daily to the catheter exit site on the back of the animal. Rats were allowed to recover for 7-10 d after surgery before self-administration experiments.

Cocaine self-administration. All self-administration sessions occurred during the light cycle at the same time of day (i.e., between 6:00 A.M. and 12:00 P.M.). Experimental sessions were conducted in operant chambers (Med Associates) as described previously (Choi et al., 2006; Edwards et al., 2007). Chambers contained two levers, one active and one inactive. Responding on the active lever resulted in delivery of an intravenous cocaine injection $(50 \mu \mathrm{l})$ delivered over $2.5 \mathrm{~s}$, and a cue light located above the lever was illuminated during the injection. A $15 \mathrm{~s}$ time-out period was initiated with the injection and signaled by the house light turning off, and active lever responding during this time was without consequence.

Cocaine self-administration on a fixed ratio schedule of reinforcement. After recovery from surgery, rats were allowed to self-administer cocaine $(0.5 \mathrm{mg} /$ $\mathrm{kg}$, i.v.) for $18 \mathrm{~d}$ on a fixed ratio 1 (FR1) schedule of reinforcement in daily $4 \mathrm{~h}$ sessions ( $6 \mathrm{~d} /$ week). Rats were initially allowed to self-administer cocaine
$4 \mathrm{~h}$ sessions for a total of $18 \mathrm{~d}$ as described above. Rats that showed stabilized self-administration on the FR5 were then separated into viral treatment groups in a counterbalanced manner to ensure similar basal levels of self-administration before treatment. Rats then underwent a 2 week period in their home cage where they were withdrawn from cocaine. At the beginning of the withdrawal period, AAV vectors were infused through NAc shell cannula to allow for maximal gene expression by the time of extinction/reinstatement testing. Two weeks after withdrawal from cocaine, rats were returned to the self-administration chambers for extinction testing in $4 \mathrm{~h}$ sessions for $6 \mathrm{~d}$, where responding on the previously cocaine-paired lever had no programmed consequence. After extinction training, rats were assessed for reinstatement of cocaineseeking behavior in five daily sessions. Reinstatement sessions consisted of $3 \mathrm{~h}$ of extinction conditions followed by exposure to a priming stimulus, and reinstatement of drug-paired lever responding was measured for an additional $1 \mathrm{~h}$ period. Priming stimuli included the noncontingent presentation of a discrete cue (stimulus light plus syringe pump sound) that previously was paired with cocaine injections (day 1), experimenteradministered cocaine injections over days $2-4$ in counterbalanced order (0, 5 , or $15 \mathrm{mg} / \mathrm{kg}$, i.p.), and exposure to intermittent footshock stress for $30 \mathrm{~min}$ on the final test session (random interval averaging $30 \mathrm{~s}, 1.0$ $\mathrm{mA} / 0.5 \mathrm{~s}$ ).

Histological localization of infusion placement. Cannulated rats that completed study were anesthetized with chloral hydrate ( $400 \mathrm{mg} / \mathrm{kg}$, i.p.) 
and cresyl violet $(0.5 \mu \mathrm{l} / \mathrm{side})$ was infused bilaterally through their indwelling cannula over a 5 min period. The rats were decapitated and the brains were sliced into $0.8 \mathrm{~mm}$ coronal sections in a brain matrix and analyzed under a dissecting microscope for location of infusion sites referenced to standard stereotaxic coordinates (Paxinos and Watson, 1998). Noncannnulated rats were anesthetized and perfused with $1 \times$ PBS followed by $4 \%$ paraformaldehyde. Brains were removed and stored in $4 \%$ paraformaldehyde overnight at $4^{\circ} \mathrm{C}$, followed by cryoprotection in $30 \%$ sucrose in $1 \times$ PBS. A microtome was used to collect $40 \mu \mathrm{m}$ sections, which were mounted on electrostatically charged slides and subjected to standard cresyl violet staining. Infusions sites were visualized in a microscope.

Statistical analysis. BDNF levels were analyzed by one-way ANOVA or a one-tailed $t$ test. Behavioral data from study groups were analyzed by twoway ANOVA with repeated measures on dose or test session. When significant main effects were found, between-group comparisons were made using Bonferroni post hoc tests. The significance level was set at $p<0.05$.

\section{Results}

Prolonged CREB overexpression in NAc shell increases BDNF and cocaine reinforcement

Figure $1 A$ shows that a $1.0 \mu$ infusion of AAV into the NAc led to long-lasting (1 month) GFP expression in an area confined to the medial shell region and did not spread into the adjacent NAc core. Both AAV-CREB and AAV-mCREB increased immunoreactivity for CREB compared to animals infused with AAV-GFP (Fig. $1 B$ ). In contrast, AAV-CREB and AAV-mCREB had opposing effects on the downstream CREB target gene BDNF (group effect: $\left.F_{(2,13)}=18.4, p<0.001\right)$, with AAV-CREB increasing BDNF protein levels by $37 \%$, and AAV-mCREB decreasing BDNF by $40 \%$ compared to AAV-GFP controls $\left({ }^{*} p<0.05\right.$; Fig. $1 C)$. These data confirm the ability of AAV-CREB and AAVmCREB to modify CREB function in the NAc shell. Only rats with correct targeting of the NAc shell subregion were used for behavioral analysis (Fig. 1D).

Rats received intra-NAc shell infusions of AAV-CREB, AAVmCREB, or AAV-GFP 7-10 d before their first selfadministration session (Fig. 2A). Neither CREB nor mCREB expression had a significant effect on the first 3 weeks of cocaine self-administration $(0.5 \mathrm{mg} / \mathrm{kg} /$ injection $)$, and rats exhibited similar stabilized levels of cocaine self-administration before dose-response testing (Fig. $2 \mathrm{~B}$ ). When the unit dose of cocaine/ injection was varied in dose-response testing, all treated groups exhibited typical inverted U-shaped dose-response curves that were dependent on cocaine dose (dose effect: $F_{(4,108)}=94.4, p<$ $0.0001)$. However, a group $\times$ dose interaction was found (interaction effect: $\left.F_{(8,108)}=3.0, p<0.01\right)$, reflecting increased cocaine self-administration rates at a threshold dose of $0.03 \mathrm{mg} / \mathrm{kg} /$ injection on the ascending limb of the dose-response curve in AAVCREB rats compared to controls expressing AAV-GFP $\left({ }^{* *} p<0.01\right.$, Fig. 2C). CREB overexpression did not alter cocaine selfadministration rates at higher doses that fall on the descending limb of the dose-response curve. These results indicate that prolonged increases in CREB activity in the NAc shell increase sensitivity to cocaine reinforcement of self-administration behavior. In contrast, prolonged decreases in NAc CREB function after AAV-mCREB treatment had no effect on cocaine self-administration rates on the fixed ratio schedule of cocaine reinforcement.

After dose-response testing on the fixed ratio schedule, cocaine self-administration was restabilized at $0.5 \mathrm{mg} / \mathrm{kg} /$ injection over 1 week. Subsequently, the motivation for cocaine was assessed using a progressive ratio schedule of cocaine reinforcement to determine the highest number of lever-press responses per injection that rats would achieve before they voluntarily ceased self-administration behavior (breakpoint). Breakpoints
A
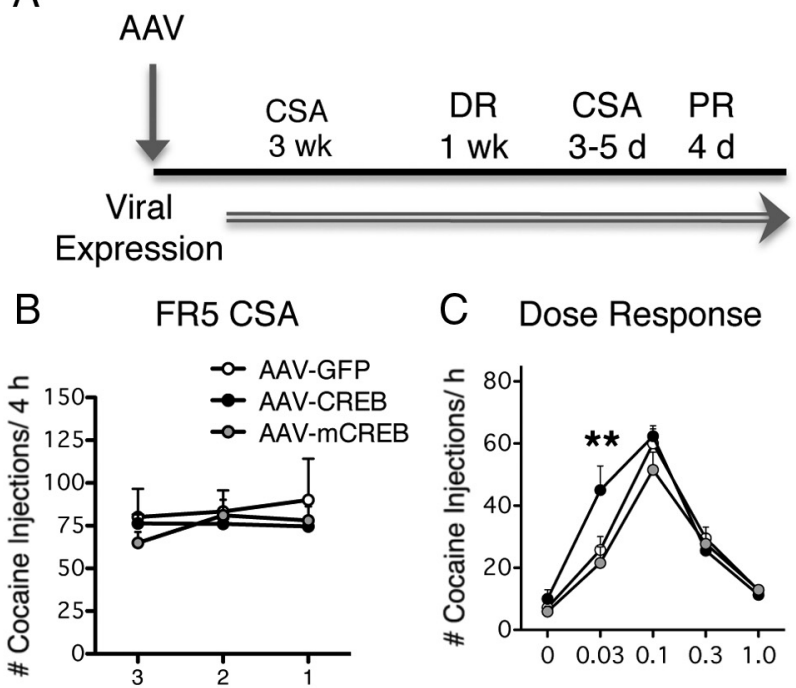

Self-administration Session
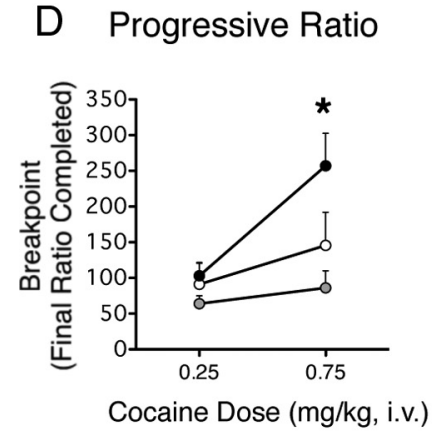

C Dose Response

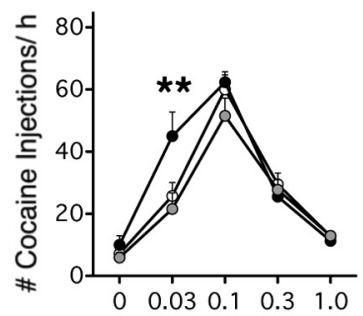

Cocaine Dose (mg/kg, i.v.)

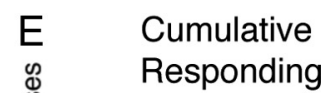

Figure 2. Effects of prolonged AAV-mediated CREB and mCREB expression in the NAc shell on cocaine self-administration. $\boldsymbol{A}$, Timeline depicting AAV infusion and serial testing of cocaine selfadministration (CSA), fixed ratio dose-response (DR), and progressive ratio (PR) cocaine reinforcement schedules. AAV vectors were infused $10 \mathrm{~d}$ before initiation of self-administration training. $\boldsymbol{B}$, Prolonged overexpression of CREB or $m$ CREB failed to affect baseline cocaine intake after stabilization on a fixed ratio 5 (FR5) schedule. C, Prolonged overexpression of CREB during dose-response testing produced a leftward shift in threshold dose sensitivity to cocaine reinforcement compared to AAV-GFP controls, while AAV-mCREB had no effect on CSA. D, Prolonged overexpression of CREB increased the effort exerted by rats to obtain cocaine injections $(0.75 \mathrm{mg} / \mathrm{kg} / \mathrm{injection})$ on the PR schedule, while prolonged $m C R E B$ expression produced minor and insignificant reductions in effort. $\boldsymbol{E}$, Individual cumulative lever-press response records for representative animals during PR testing for cocaine injections (circles). The number of responses required for the final cocaine injection before voluntary cessation of self-administration (breakpoint) is represented by dotted lines with double-ended arrows. Asterisks indicate significant differences from GFP controls by Bonferroni tests ${ }^{*} p<0.05$, ${ }^{* *} p<0.01 ; n=8-12 /$ group).

were determined for both 0.25 and $0.75 \mathrm{mg} / \mathrm{kg} /$ injection in successive tests, and animals generally worked harder for the higher injection dose (dose effect: $F_{(1,26)}=17.1, p<0.001$ ), indicating greater motivation to self-administer the higher dose of cocaine (Fig. 2D). Overexpression of CREB and mCREB differentially altered cocaine self-administration breakpoints (group effect: $\left.F_{(2,26)}=3.4, p<0.05\right)$, and these effects varied as a function of cocaine dose (interaction effect: $F_{(2,26)}=4.3, p<0.05$ ). AAVCREB-infused animals achieved markedly higher breakpoints than AAV-GFP-infused controls at the $0.75 \mathrm{mg} / \mathrm{kg}$ cocaine injection dose $\left({ }^{*} p<0.05\right)$, indicating that prolonged CREB overexpression increases the motivation for cocaine. Cumulative response records from representative animals self-administering $0.75 \mathrm{mg} / \mathrm{kg} /$ injection show that a typical rat overexpressing CREB performed 219 lever-press responses for the final cocaine injec- 
A

B
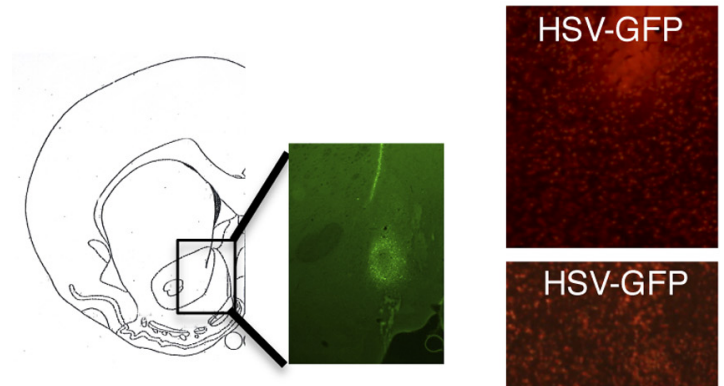

HSV-GFP

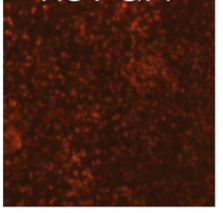

C

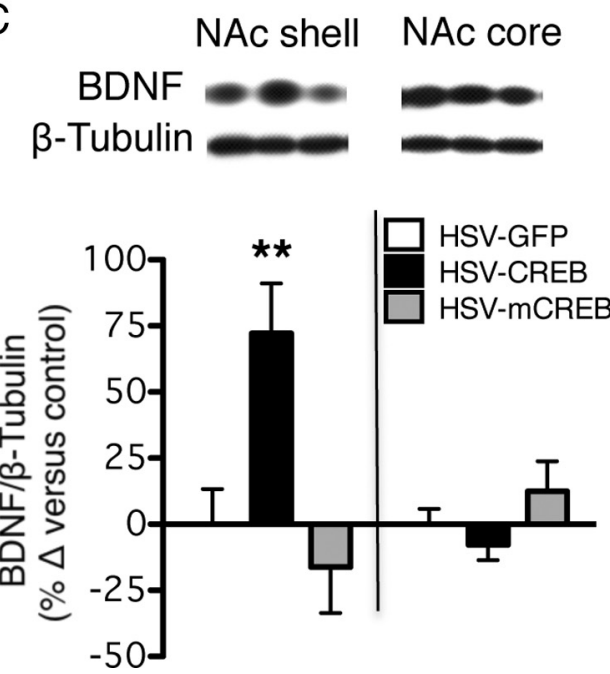

D
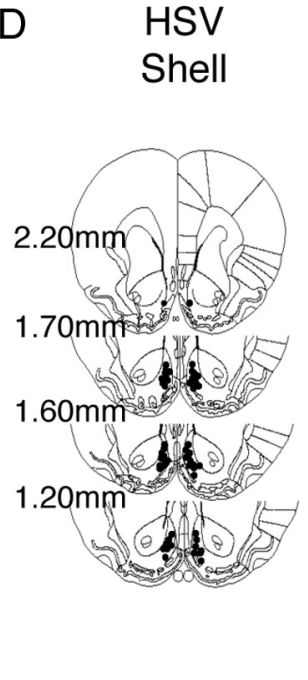

Figure 3. Effects of HSV-CREB and HSV-mCREB on BDNF levels in the NAc. $A$, Representation of localized GFP immunoreactivity in the NAc shell $3 \mathrm{~d}$ after a single HSV infusion ( $40 \mu \mathrm{m}$ coronal section, $10 \times$ ). $\boldsymbol{B}$, Increase in (REB immunoreactivity in the NAc shell $3 \mathrm{~d}$ after a single infusion of either HSV-CREB or HSV-mCREB compared to HSV-GFP controls $(40 \times)$. C, Western blot of BDNF protein levels in the NAc shell and core $3 \mathrm{~d}$ after a second infusion of the HSV vectors in the NAc shell ( $n=4-6 /$ group). HSV-CREB increased BDNF levels while HSV-mCREB failed to significantly alter BDNF levels compared to HSV-GFP infused controls by Bonferroni tests $\left({ }^{* *} p<0.01\right)$. D, Localization of NAc shell HSV infusion sites for animals tested in cocaine self-administration shown in Figure 4.

tion, while a GFP-expressing control rat only achieved 118 responses per injection before cessation of self-administration behavior (Fig. 2E). Conversely, a rat overexpressing mCREB achieved an even lower response/injection ratio of 50 lever presses, although the reduction in overall mean breakpoints from 149 ( \pm 52.5 ) responses in GFP controls to 86 ( \pm 23.9 ) responses in mCREB-expressing animals failed to achieve statistical significance.

\section{Transient CREB overexpression after acquisition of self-administration also increases BDNF and cocaine reinforcement}

We used the transient expression profile of HSV-CREB vectors to study the direct effect of CREB on cocaine reinforcement independent of interactions during acquisition of cocaine self-administration. HSV-mediated expression has been shown to peak by $3 \mathrm{~d}$ postinfusion and return to basal levels by $6 \mathrm{~d}$ postinfusion (Barrot et al., 2002). HSV infusions selectively targeted expression to the NAc shell subregion (Fig. $3 A$ ), and both HSV-CREB and HSV-mCREB increased CREB immunoreactivity (Fig. $3 B$ ) similar to prolonged expression with AAV infusions. However, while prolonged AAVmediated CREB overexpression increased BDNF by $37 \%$ in NAc shell homogenates, transient CREB overexpression by a single HSV
HSV Shell

infusion induced $\sim 4$ fold greater $159 \%$ increase in BDNF protein levels $\left(F_{(2,19)}=4.0\right.$, $p=0.039$, data not shown). To parallel the behavioral experiments, a second HSV infusion was administered in cannulated rats $17 \mathrm{~d}$ later, and this infusion also increased BDNF levels 3 d later (group effect: $F_{(2,19)}=$ 10.3, $p=0.001$, Fig. 3C) albeit to a lesser extent $(72 \%)$. In contrast to AAV-mCREB, HSV-mCREB failed to significantly decrease BDNF levels, suggesting that prolonged expression of the dominant negative is necessary for loss of CREB activity at this target gene. Localization of NAc shell infusion sites for rats used in the behavioral analysis is shown (Fig. 3D).

For the HSV self-administration experiment, rats were trained to acquire cocaine self-administration and subjected to withinsession dose-response testing for 1 week in the absence of CREB overexpression (Fig. $4 A$ ). Baseline dose-response data were averaged for the last 2 sessions before HSV infusions (Fig. 4B). Rats received intra-NAc shell infusions of HSV-GFP, HSV-CREB, or HSV-mCREB and were tested again on the dose-response during CREB overexpression; data from days 3-4 postinfusion were averaged to assess the direct effects of CREB on the dose-response curve (Fig. 4C). During HSV-mediated expression, dose-dependent self-administration of cocaine was evident in all groups (dose effect: $\left.F_{(4,195)}=72.5, p<0.001\right)$, but transient CREB overexpression produced a vertical shift in the dose-response curve (group effect: $F_{(2,195)}=5.7, p<0.01$ ), primarily due to increases in peak selfadministration rates at the $0.1 \mathrm{mg} / \mathrm{kg} /$ injection dose $\left({ }^{*} p<0.05\right)$ and consistent with an enhancement in cocaine reinforcement. Transient overexpression of $\mathrm{mCREB}$ failed to alter cocaine intake during doseresponse testing, consistent with the lack of regulation in BDNF. When tested the following week after HSV-mediated expression had dissipated, cocaine self-administration dose-response curves returned to pre-HSV baselines in HSV-CREB-treated animals (data not shown), indicating that CREB expression directly alters cocaine reinforcement independently of potential interactions during acquisition of self-administration.

After dose-response testing, rats were restabilized on the FR5 schedule and then infused with a second round of HSV-GFP, HSV-CREB, or HSV-mCREB before progressive ratio testing as depicted in Figure $4 A$. Transient overexpression of CREB produced a significant increase in breakpoints for cessation of cocaine self-administration (group effect: $F_{(2,29)}=3.6, p<0.05$, Fig. $4 D$ ), achieving significance at the higher $0.75 \mathrm{mg} / \mathrm{kg} / \mathrm{injec}-$ tion dose when compared to GFP controls $\left({ }^{*} p<0.05\right)$. All groups showed increased responding for the higher injection dose (dose effect: $F_{(1,29)}=14.3, p<0.001$, Fig. $4 D$ ), although no interaction was found. Cumulative response records from representative animals self-administering at $0.75 \mathrm{mg} / \mathrm{kg} /$ injection show that a typical rat with transient CREB overexpression performed 328 lever-press responses for the final cocaine injection compared with 118 
lever-press responses/injection in a GFPexpressing control (Fig. 4E). These HSV data indicate that CREB overexpression produces a direct enhancement in the motivation for $\mathrm{CO}^{-}$ caine independent of potential interactions during acquisition and maintenance of cocaine self-administration. In contrast to minor decreases in breakpoints with prolonged overexpression of dominant-negative mCREB in $\mathrm{AAV}$-infused animals, there was no effect of transient HSV-mediated mCREB overexpression on cocaine self-administration breakpoints, consistent with its lack of effect on BDNF levels.

\section{Reduction of endogenous CREB in the NAc shell reduces cocaine reinforcement}

Given that overexpression of dominantnegative mCREB failed to significantly alter cocaine self-administration, we used an RNA interference approach to selectively reduce CREB levels in the NAc shell. The CREB-RNAi was expressed in an AAV viral vector, and so it was administered as described above with AAV-CREB (Fig. 6A). AAV-CREB-RNAi infusions led to selective expression in the NAc shell subregion similar to other vectors (Fig. 5A). AAV-CREB-RNAi reduced endogenous CREB immunoreactivity (Fig. 5B) and produced a larger $51 \%$ reduction in basal BDNF protein levels (group effect: $t_{(1,8)}=1.8, p=0.05$, Fig. $5 C$ ) compared to the $40 \%$ reduction produced by AAV-mCREB.

There was no effect of CREB-RNAi expression on stabilized levels of cocaine self-administration before fixed ratio doseresponse testing (Fig. 6B), and all rats exhibited dose-dependent self-administration rates during dose-response testing (dose effect: $F_{(4,144)}=2.3, p<0.001$, Fig. 6C). However, AAV-CREB-RNAiinduced reductions in endogenous CREB in the NAc shell led to prominent alterations in the cocaine self-administration dose-response curve compared to control infusions with AAV-scr-RNAi (group effect: $\left.F_{(1,144)}=5.8, p<0.05\right)$, primarily at the threshold dose of $0.03 \mathrm{mg} / \mathrm{kg} /$ injection compared to controls expressing scr-RNAi $\left.{ }^{* *} p<0.01\right)$. These results indicate that a prolonged reduction in CREB levels in the NAc shell decreases sensitivity to cocaine reinforcement. Moreover, AAV-CREB-RNAi infusions produced a significant overall reduction in breakpoints for cessation of cocaine self-administration on the progressive ratio schedule (group effect: $F_{(1,36)}=4.6, p<0.05$ ), and this was particularly evident at the higher cocaine injection dose $\left({ }^{\star} p<\right.$ 0.05 , Fig. $6 D$ ), although all groups showed dose-dependent increases in breakpoints (dose effect: $F_{(1,36)}=42.1, p<$ $0.001)$. These data indicate that loss of CREB in NAc shell neurons reduces the motivation for cocaine. This effect is illustrated in representative animals self-administering 0.75 $\mathrm{mg} / \mathrm{kg} /$ injection cocaine, where a rat overexpressing AAVCREB-RNAi reached a break point of only 95 lever-press responses/injection compared to 178 responses for a AAV-scrRNAi infused control (Fig. 6E). Localization of NAc shell infusion sites for rats used in the behavioral analysis is shown (Fig. 5D).

\section{CREB effects on cocaine reinforcement are correlated with BDNF alterations in the NAc shell}

We compared the ability of the AAV, HSV, and AAV-RNAi viruses to alter the expression of the downstream CREB target BDNF with their ability to alter breakpoints for cocaine selfadministration at both the 0.25 and $0.75 \mathrm{mg} / \mathrm{kg}$ injection doses of cocaine (Fig. $7 A, B$ ). Interestingly, we found strong positive cor- 
A

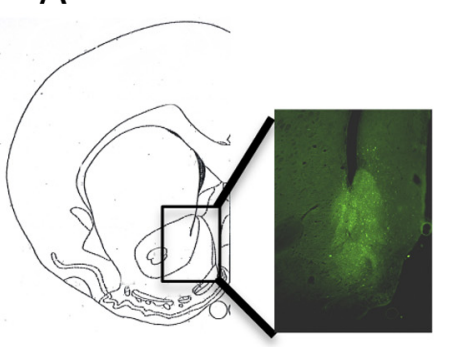

B

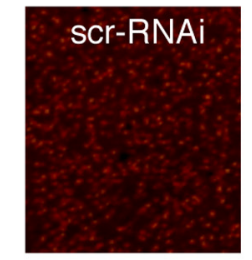

C

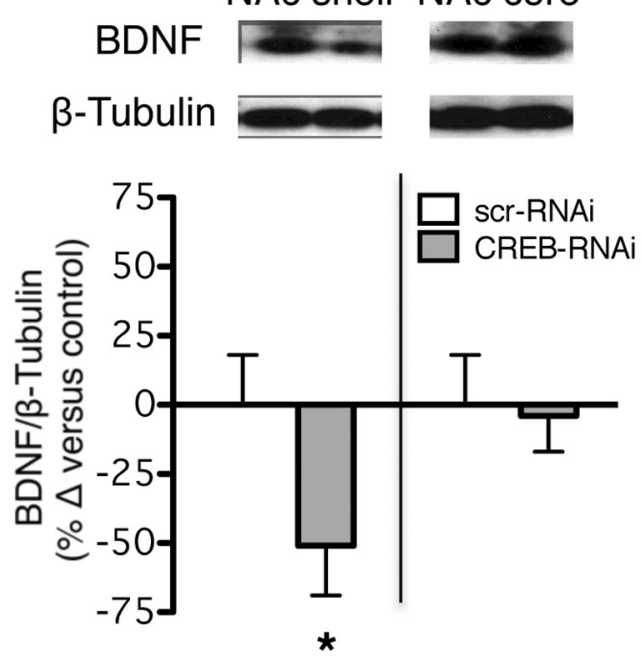

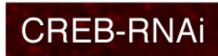

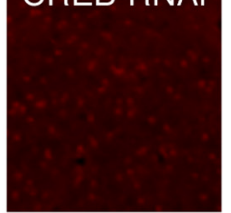

D AAV-RNAI Shell

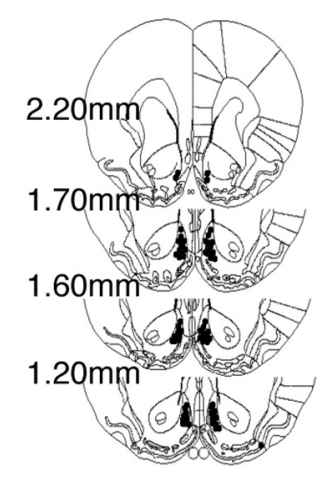

Figure 5. Effects of AAV-CREB-RNAi on BDNF levels in the NAc. $\boldsymbol{A}$, Representation of localized GFP immunoreactivity in the NAc shell 1 month after AAV infusion ( $40 \mu \mathrm{m}$ coronal section, 10X). $B$, Decrease in (REB immunoreactivity in the NAc shell 1 month after infusion of AAV-CREB-RNAi compared to AAV-scr-RNAi control $(40 \times)$. C, Western blot of BDNF protein levels in the NAC shell and core 1 month after infusion of the AAV vectors in the NAc shell ( $n=5 /$ group). AAV-CREB-RNAi decreased BDNF levels compared to AAV-scr-RNAi controls by $t$ test $\left({ }^{*} p<0.05\right)$. D, Localization of NAc shell AAV infusion sites for animals tested in cocaine self-administration shown in Figure 6.

relations that approached unity between viral-mediated BDNF alterations and the effort exerted by rats to obtain either the 0.25 $\mathrm{mg} / \mathrm{kg}$ injection dose $\left(r^{2}=0.9680, p<0.01\right)$ or the $0.75 \mathrm{mg} / \mathrm{kg}$ injection dose $\left(r^{2}=0.9699, p<0.01\right)$. Thus, HSV-CREB produced the greatest increases in BDNF levels ( $72 \%$ increase) and the largest elevations in breakpoints when working for the 0.25 and $0.75 \mathrm{mg} / \mathrm{kg}$ cocaine injection doses (62 and 173\% increase, respectively), while rats treated with AAV-CREB-RNAi produced the strongest reduction in BDNF levels ( $51 \%$ decrease) and the largest decrease in breakpoints at the 0.25 and $0.75 \mathrm{mg} / \mathrm{kg}$ injection doses ( 45 and 39\% decrease, respectively). These results indicate that that the magnitude of alteration in CREB function at the downstream BDNF gene is strongly associated with cocaine reinforcement of self-administration behavior.

\section{CREB function in NAc shell is involved in relapse to cocaine} seeking after withdrawal from cocaine

To determine whether CREB function in the NAc shell directly modulates relapse to cocaine-seeking behavior, rats were infused with AAV-CREB, AAV-CREB-RNAi, or the appropriate control vector in the NAc shell after withdrawal from 3 weeks of chronic cocaine self-administration (Fig. $8 \mathrm{~A}$ ). Rats were assigned treatments so that stabilized cocaine intake was similar across study groups (Fig. 8C,F). We found that increasing or decreasing CREB function in the NAc shell had differential and opposing effects on cocaine-seeking behavior depending on the extinction/reinstate- ment test employed. Thus, overexpression of CREB during withdrawal had no effect on rate of extinction of cocaineseeking behavior when rats were returned to self-administration chambers in the absence of cocaine reinforcement. However, overexpression of CREB led to an increase in cocaine-primed reinstatement of drugpaired lever responding compared to GFP controls after extinction training (group effect: $F_{(1,84)}=4.4, p<0.05$, Fig. $8 E$ ). There was no effect on reinstatement elicited by exposure to injection cues or following a brief $30 \mathrm{~min}$ period of intermittent footshock stress. Conversely, reducing endogenous CREB function with CREB-RNAi facilitated extinction of cocaineseeking behavior compared to scr-RNAi controls (group effect: $F_{(5,85)}=3.7, p<$ 0.01 , Fig. $8 G$ ), particularly during the initial extinction session $\left({ }^{* *} p<0.01\right)$, but failed to alter reinstatement of cocaine seeking induced by cocaine priming, cocaine cues, or footshock stress (Fig. $8 H$ ). This finding indicates that CREB can play a necessary role in cocaine seeking in the absence of cocaine exposure. The lack of significant attenuation of cocaine-primed reinstatement differs from the strong reduction in motivation for responsecontingent cocaine injections during progressive ratio cocaine self-administration, suggesting that CREB plays a necessary role in the reinforcing context of cocaine administration.

Rats in all groups extinguished to similar response rates before reinstatement testing (Fig. 8D,G) and showed dose-dependent reinstatement with cocaine priming injections (effect of dose: AAV-CREB, $F_{(2,84)}=22.5, p<0.001$; AAV-CREB-RNAi, $F_{(5,85)}=48.7, p<$ $0.001)$. All groups also showed effective reinstatement by cues (effect of stimulus: AAV-CREB, $F_{(1,28)}=13.2, p=0.001$; AAVCREB-RNAi, $F_{(1,17)}=9.6, p<0.01$ ) and stress (effect of stimulus: AAV-CREB, $F_{(1,27)}=13.3, p=0.001$; AAV-CREB-RNAi, $\left.F_{(1,17)}=12.0, p<0.01\right)$ compared to the $1 \mathrm{~h}$ period preceding stimulus presentation. Localization of NAc shell infusion sites for rats included in the analysis of these data is shown in Figure $8 B$.

\section{Discussion}

We found that CREB activity in the NAc shell plays both sufficient and necessary roles in modulating cocaine reinforcement of self-administration behavior. Thus, viral-mediated upregulation of CREB increases responding for low cocaine doses at the threshold for maintaining self-administration behavior, and rats exert far greater effort to self-administer higher cocaine doses with progressive increases in response demands. These findings indicate that NAc CREB activity produces an overall enhancement of cocaine reinforcement in self-administering animals. Conversely, RNAi-mediated downregulation of endogenous CREB reduces self-administration of low cocaine dose, and reduces the motivation to self-administer higher cocaine doses, indicating an attenuation of cocaine reinforcement consistent with our previ- 
A

AAV

CSA DR CSA PR 3 weeks 1 week 3-5 days 4 days Expression
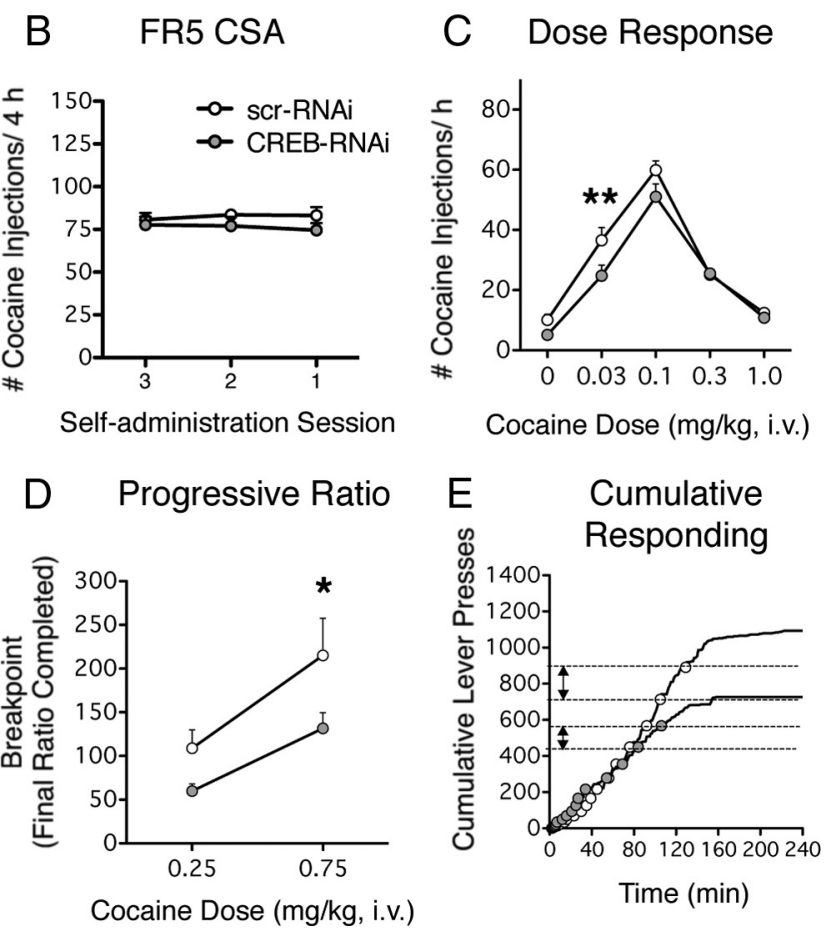

Figure 6. Effects of AAV-CREB-RNAi-mediated reduction in endogenous CREB in the NAC shell on cocaine self-administration. $\boldsymbol{A}$, Timeline depicting AAV infusion and serial testing of cocaine self-administration (CSA), fixed-ratio dose-response (DR), and progressive ratio (PR) reinforcement schedules. $A A V$ vectors were infused $10 \mathrm{~d}$ before initiation of self-administration training. $\boldsymbol{B}$, Continuous overexpression of CREB-RNAi failed to affect baseline cocaine intake after stabilization on a fixed ratio 5 (FR5) schedule compared to AAV-scr-RNAi controls. C, CREB-RNAi-mediated decreases in endogenous CREB levels produced a decrease in threshold dose sensitivity to cocaine reinforcement compared to AAV-scr-RNAi controls. D, CREB-RNAimediated reductions in CREB decreased the effort exerted by rats to achieve cocaine injections $(0.75 \mathrm{mg} / \mathrm{kg} /$ injection) on the PR schedule. $\boldsymbol{E}$, Individual cumulative lever-press response records for representative animals during PR testing for cocaine injections (circles). The number of responses required for the final cocaine injection before voluntary cessation of selfadministration (breakpoint) is represented by dotted lines with double-ended arrows. Asterisks indicate significant differences from scr-RNAi controls by Bonferroni tests $\left({ }^{*} p<0.05,{ }^{* *} p<\right.$ $0.01 ; n=17-21 /$ group).

ous work using antisense oligonucleotides to lower NAc CREB levels (Choi et al., 2006).

Importantly, the effects of modulating NAc shell CREB in cocaine self-administering animals are diametrically opposite to the effects on cocaine reward using the Pavlovian-based CPP approach, where CREB is shown to mediate a tolerancelike attenuation of cocaine-induced place preference (Carlezon et al., 1998; Pliakas et al., 2001). This discrepancy is likely related to volitional control over cocaine intake in selfadministering animas versus passive experimenter-delivered cocaine with place-conditioning procedures. Thus, in CPP studies, a preference for the cocaine-paired environment is based on the magnitude of the pharmacological stimulus produced by cocaine, and NAc CREB activity may blunt the intensity of this effect. In contrast, the motivation to self-
A

$0.25 \mathrm{mg} / \mathrm{kg}$ cocaine $(\mathrm{PR})$

$r^{2}=0.9680, p=0.0025$
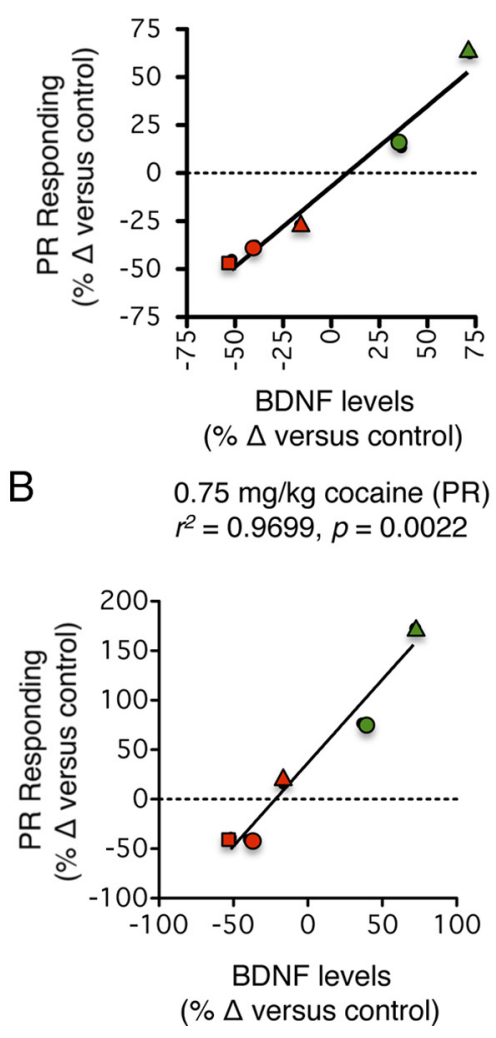

Figure 7. Positive correlation between the ability of CREB viral vectors to alter endogenous levels of BDNF and their ability to alter breakpoints during progressive ratio (PR) testing. $A, P R$ responding at the $0.25 \mathrm{mg} / \mathrm{kg}$ cocaine dose $\left(r^{2}=0.9680, p<0.01\right) . B$, PR responding at the $0.75 \mathrm{mg} / \mathrm{kg}$ cocaine dose $\left(r^{2}=0.9699, p<0.01\right)$. Circles represent AAV-CREB (green) and AAV-mCREB (red), triangles represent HSV-CREB (green) or HSV-mCREB (red), and the red square represents the AAV-CREB-RNAi vector.

administer cocaine is influenced by a variety of emotional factors in addition to the pharmacological impact of the cocaine injections. For example, overexpression of CREB in the shell produces depressive-like behavior in forced swim tests and enhances the aversive effects of cocaine withdrawal (Pliakas et al., 2001), and the ability of cocaine to alleviate these dysphoric/depressive effects may enhance the motivation to self-administer cocaine (negative reinforcement). This idea is supported by findings that CREB overexpression increases, while mCREB decreases, the intrinsic excitability of NAc neurons (Dong et al. 2006; Huang et al. 2008), and that elevated excitability of NAc neurons may be associated with aversive behavioral states (Carlezon and Thomas, 2009). Alternatively, CREB activity in the NAc shell dampens reactivity to anxiogenic stimuli (Barrot et al., 2002), which could facilitate cocaine self-administration by reducing the anxiogenic effects of intravenous cocaine injections (Geist and Ettenberg, 1997). However, NAc CREB fails to increase unencumbered cocaine intake, which does not support its role in tolerance or other factors that lead to escalation of cocaine intake with the development of cocaine addiction (Koob and Le Moal, 2008; Koob, 2009).

Impairments in NAc CREB enhance the sensitivity to low cocaine doses in CPP and brain stimulation reward studies (Carlezon et al., 1998; Pliakas et al., 2001; Dinieri et al., 2009), whereas we found 
A

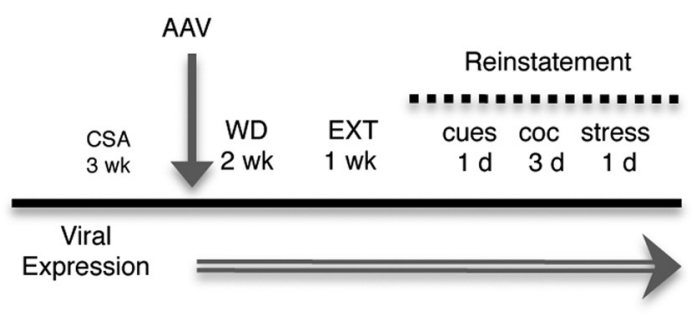

B AAV-CREB AAV-CREB-RNAi

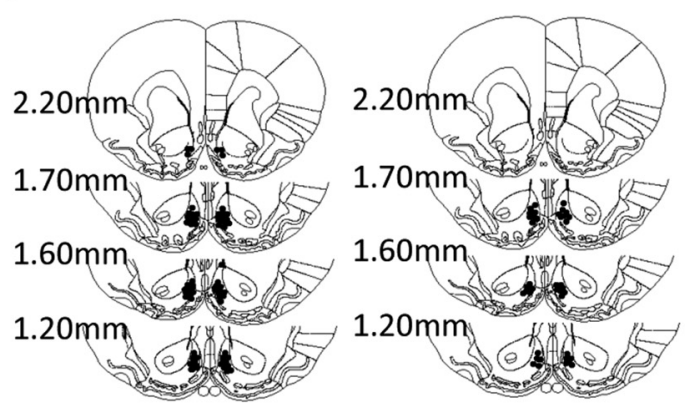

C FR5 CSA D Extinction E

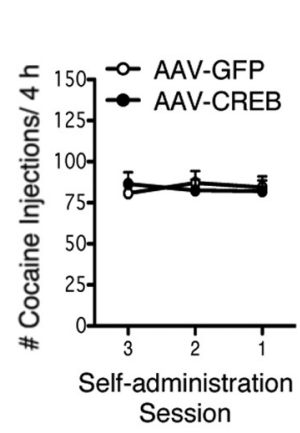

F FR5 CSA
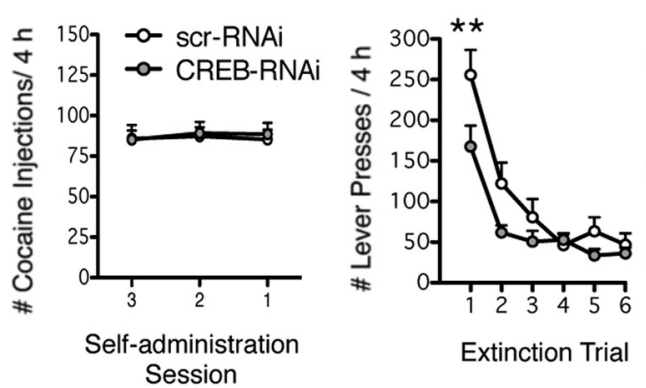

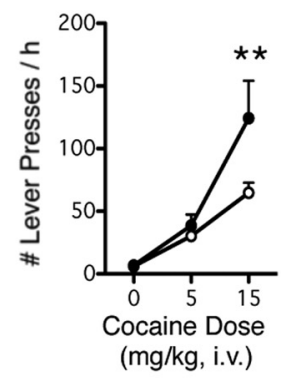

$\mathrm{H}$

\section{Reinstatement}

Cocaine Prime Cues
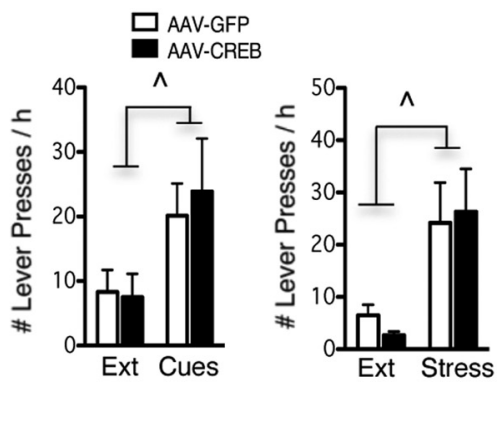

Reinstatement

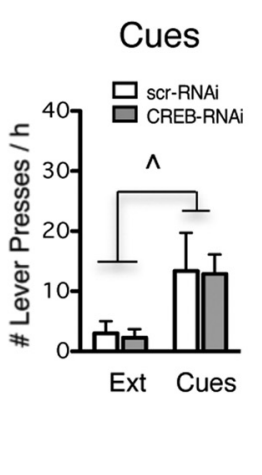

Footshock

Figure 8. Effects of modulating CREB in the NAc shell after withdrawal from cocaine (WD) on extinction and reinstatement of cocaine-seeking behavior. $\boldsymbol{A}$, Timeline depicting cocaine self-administration (CSA), AAV infusion, and subsequent extinction (EXT)/reinstatement testing. AAV vectors were infused $1 \mathrm{~d}$ after the final cocaine self-administration session 2 weeks before the onset of extinction/reinstatement testing. $\boldsymbol{B}$, Localization of NAc shell AAV infusion sites for animals tested in extinction/reinstatement. $\boldsymbol{C}, \boldsymbol{F}$, Study groups exhibited similar stabilized CSA before AAV infusions. $D, G$, vverexpression of CREB (AAV-CREB) had no prominent effect on extinction of cocaine seeking, while reductions in endogenous CREB levels (AAV-CREB-RNAi) reduced drug-paired lever responding in initial extinction trials. $\boldsymbol{E}, \boldsymbol{H}, 0$ verexpression of CREB increased cocaine-primed reinstatement of drug-paired lever responding, while reductions in endogenous $C R E B$ levels had no significant effect. Neither CREB nor CREB-RNAi altered reinstatement induced by cocaine-conditioned cues or 30 min exposure to intermittent footshock stress. The caret $(\wedge)$ symbol indicates a significant difference in lever responding after exposure to priming stimuli $(\wedge p<0.01)$, and asterisks indicate significant differences from controls by Bonferroni tests $\left({ }^{* *} p<0.01 ; n=\right.$ 9-15/group).

that impaired CREB activity decreases cocaine reinforcement in self-administering animals. Reduced self-administration of low threshold cocaine doses is remarkably similar to the effect of environmental enrichment, and environmental enrichment also decreases NAc CREB activity while enhancing cocaine CPP (Green et al., 2010). Moreover, environmental enrichment increases anxietylike behavior while reducing depressive-like behavior, similar to the effects of blocking NAc CREB activity (Pliakas et al., 2001; Barrot et al., 2002; Newton et al., 2002; Wallace et al., 2009; Green et al., 2010). Together, these findings suggest that lower NAc CREB activity reduces cocaine self-administration by removing the negative rein- forcing and/or augmenting the anxiogenic effects of the intravenous cocaine injections.

NAc CREB activity is important for the acquisition of cocaineconditioned behavior (Miller and Marshall, 2005; Kuo et al., 2007; Shiflett et al., 2009). Thus, prolonged CREB activation in the NAc could strengthen reinforcement-related learning and memory during acquisition of cocaine self-administration. However, transient CREB overexpression following acquisition also increases cocaine reinforcement, suggesting that CREB directly augments cocaine reinforcement independently of instrumental learning. While CREB activity modulates self-administration of 
both freely available low-dose cocaine injections and responding for higher doses on the more demanding progressive ratio schedule, CREB fails to alter fixed ratio self-administration of higher doses (0.3-1.0 mg/kg/injection), indicating that changes in progressive ratio responding are related to motivational effects rather than generalized changes in instrumental behavior.

The ability of CREB viral vectors to induce downstream regulation of BDNF is strongly and positively correlated with increases in cocaine reinforcement measured in progressive ratio testing. These results are consistent with our previous work showing that NAc shell infusions of BDNF increase the motivation for cocaine under similar testing conditions (Graham et al., 2007). In addition, intra-NAc shell infusions of BDNF also lead to tolerance-like increases in the rate of cocaine intake on fixedratio reinforcement schedules, effects that are not found with increasing CREB activity in the present study. These differences suggest that other CREB target genes may have obscured a tolerance-like effect of BDNF in the NAc shell. Moreover, the development of tolerance-like escalation in cocaine intake is associated with dorsal striatal upregulation of both CREB activity and BDNF through complex and opposing interactions with microRNA-212 and the transcriptional repressor MeCP2 (Hollander et al., 2010; Im et al., 2010). However, these studies report opposite effects of CREB and BDNF on cocaine intake and the motivation for cocaine, with CREB reducing and BDNF enhancing cocaine reinforcement. Thus, CREB may play fundamentally different roles in cocaine addiction in dorsal and ventral striatal subregions via differential transcriptional interactions with BDNF expression. Given the correlative nature of our results, further work is needed to determine whether BDNF is necessary for the enhancement of cocaine reinforcement by CREB in the NAc shell, or whether other CREB-regulated genes are involved.

We found that dominant-negative $\mathrm{MCREB}$ produces a relatively weaker (AAV) or lack of (HSV) effect on BDNF levels in the shell, potentially due to its transient expression profile (HSV), and this is consistent with its poor efficacy in modulating cocaine self-administration despite similar increases in ectopic CREBlike immunoreactivity. The $\mathrm{mCREB}^{\mathrm{S} 133 \mathrm{~A}}$ protein dimerizes with endogenous CREB and binds to CRE-sites on DNA but cannot be phosphorylated, leading to impaired CRE-regulated gene expression by several CREB-family transcription factors (Gonzalez and Montminy, 1989). A rich literature shows that NAc mCREB expression produces behavioral effects opposite to those of CREB (Carlezon et al., 1998; Pliakas et al., 2001; Barrot et al., 2002; Wallace et al., 2009), and reasons for a lack of effect here are unknown but could involve the high degree of cocaine exposure in self-administering animals relative to previous work in drugnaive animals.

In addition to modulation of cocaine self-administration, we found that increasing CREB expression after withdrawal from cocaine is sufficient to facilitate relapse to cocaine seeking triggered by cocaine priming injections without altering cocaine seeking during extinction or elicited by discrete injection cues and exposure to stress. These results suggest that CREB effects are limited to modulating motivational responses to cocaine. However, RNAi-induced decreases in CREB initiated after withdrawal from cocaine reduce cocaine-seeking behavior with initial exposure to extinction conditions, indicating that endogenous CREB can alter motivation for cocaine even in the absence of the drug. In contrast, brain-wide CREB knock-out blocks stress-induced, but not cocaine-induced, reinstatement of cocaine CPP (Walters and Blendy, 2001). These discrepancies also could involve paradigmatic differences between CPP and self-administration or al- terations in CREB function outside of the NAc in $\mathrm{CREB}^{\alpha \Delta}$ mutant mice (Kreibich et al., 2009).

CREB effects on cocaine seeking after cocaine withdrawal partially overlap with BDNF effects in the NAc shell (Graham et al., 2007), similar to cocaine self-administration. Thus, both CREB and BDNF increase reinstatement induced by cocaine priming injections, but only BDNF increases reinstatement by cues or footshock stress. Like BDNF, CREB also increases expression of the $\kappa$ opiate receptor peptide dynorphin in the NAc shell, and both dynorphin and BDNF increases in the NAc are associated with depressed behavioral states (Pliakas et al., 2001; Krishnan et al., 2007). While CREB regulation of dynorphin or other genes could counteract BDNF effects on cue-and stress-primed relapse, other CREB effects generally are not consistent with regulation of dynorphin, because systemic pretreatment with $\kappa$ agonists inhibits cocaine-primed reinstatement of cocaine seeking (Schenk et al., 1999; Ruedi-Bettschen et al., 2010) and reduces cocaine selfadministration rates (Negus et al., 1997; Schenk et al., 1999; Wee et al., 2009). In contrast, another study found increased sensitivity to low threshold dose cocaine self-administration with $\kappa$ agonist pretreatment (Kuzmin et al., 1997), similar to CREB effects on cocaine self-administration in our study. Thus, CREB regulation of dynorphin expression could facilitate self-administration of low cocaine doses, whereas a CREB-BDNF signaling cascade may increase the motivational response to higher doses during self-administration and relapse (Graham et al., 2007).

In conclusion, CREB activity in the NAc shell facilitates cocaine reinforcement of self-administration behavior, arguably a direct measure of the motivation for cocaine and different from opposite effects in previous CPP studies, but also a highly pertinent test of human abuse liability and vulnerability to drug addiction. The ability of CREB to alter the motivation for cocaine is tightly correlated with BDNF induction and can extend after cocaine withdrawal with reexposure to cocaine or cocaineassociated environments. These findings highlight the importance of ultimately using self-administration methods to investigate the functional relevance of drug-induced neuroadaptations on complex behaviors relating to addiction.

\section{References}

Barrot M, Olivier JD, Perrotti LI, DiLeone RJ, Berton O, Eisch AJ, Impey S, Storm DR, Neve RL, Yin JC, Zachariou V, Nestler EJ (2002) CREB activity in the nucleus accumbens shell controls gating of behavioral responses to emotional stimuli. Proc Natl Acad Sci U S A 99:11435-11440.

Berger AK, Green T, Siegel SJ, Nestler EJ, Hammer RP Jr (2011) cAMP response element binding protein phosphorylation in nucleus accumbens underlies sustained recovery of sensorimotor gating following repeated $\mathrm{D}_{2}$-like receptor agonist treatment in rats. Biol Psychiatry 69:288-294.

Carlezon WA Jr and Thomas MJ (2009) Biological substrates of reward and aversion: a nucleus accumbens activity hypothesis. Neuropharmacol 56 [Suppl 1]:122-132.

Carlezon WA Jr, Thome J, Olson VG, Lane-Ladd SB, Brodkin ES, Hiroi N, Duman RS, Neve RL, Nestler EJ (1998) Regulation of cocaine reward by CREB. Science 282:2272-2275.

Carlezon WA Jr, Duman RS, Nestler EJ (2005) The many faces of CREB. Trends Neurosci 28:436-445.

Chartoff EH, Papadopoulou M, Konradi C, Carlezon WA Jr (2003) Dopamine-dependent increases in phosphorylation of cAMP response element binding protein (CREB) during precipitated morphine withdrawal in primary cultures of rat striatum. J Neurochem 87:107-118.

Choi KH, Whisler K, Graham DL, Self DW (2006) Antisense-induced reduction in nucleus accumbens cyclic AMP response element binding protein attenuates cocaine reinforcement. Neuroscience 137:373-383.

Dinieri JA, Nemeth CL, Parsegian A, Carle T, Gurevich VV, Gurevich E, Neve RL, Nestler EJ, Carlezon WA Jr (2009) Altered sensitivity to rewarding and aversive drugs in mice with inducible disruption of cAMP response 
element-binding protein function within the nucleus accumbens. J Neurosci 29:1855-1859.

Dong Y, Green T, Saal D, Marie H, Neve R, Nestler EJ, Malenka RC (2006) CREB modulates excitability of nucleus accumbens neurons. Nat Neurosci 9:475-477.

Edwards S, Whisler KN, Fuller DC, Orsulak PJ, Self DW (2007) Addictionrelated alterations in D1 and D2 dopamine receptor behavioral responses following chronic cocaine self-administration. Neuropsychopharmacology 32:354-366.

Geist TD, Ettenberg A (1997) Concurrent positive and negative goalbox events produce runway behaviors comparable to those of cocainereinforced rats. Pharmacol Biochem Behav 57:145-150.

Gonzalez GA, Montminy MR (1989) Cyclic AMP stimulates somatostatin gene transcription by phosphorylation of CREB at serine 133. Cell 59:675-680.

Graham DL, Edwards S, Bachtell RK, DiLeone RJ, Rios M, Self DW (2007) Dynamic BDNF activity in nucleus accumbens with cocaine use increases self-administration and relapse. Nat Neurosci 10:1029-1037.

Green TA, Alibhai IN, Roybal CN, Winstanley CA, Theobald DE, Birnbaum SG, Graham AR, Unterberg S, Graham DL, Vialou V, Bass CE, Terwilliger EF, Bardo MT, Nestler EJ (2010) Environmental enrichment produces a behavioral phenotype mediated by low cyclic adenosine monophosphate response element binding (CREB) activity in the nucleus accumbens. Biol Psychiatry 67:28-35.

Hollander JA, Im HI, Amelio AL, Kocerha J, Bali P, Lu Q, Willoughby D, Wahlestedt C, Conkright MD, Kenny PJ (2010) Striatal microRNA controls cocaine intake through CREB signalling. Nature 466:197-202.

Huang YH, Lin Y, Brown TE, Han MH, Saal DB, Neve RL, Zukin RS, Sorg BA, Nestler EJ, Malenka RC, Dong Y (2008) CREB modulates the functional output of nucleus accumbens neurons: a critical role of N-methyl-Daspartate glutamate receptor (NMDAR) receptors. J Biol Chem 283: 2751-2760.

Im HI, Hollander JA, Bali P, Kenny PJ (2010) MeCP2 controls BDNF expression and cocaine intake through homeostatic interactions with microRNA-212. Nat Neurosci 13:1120-1127.

Koob GF (2009) Neurobiological substrates for the dark side of compulsivity in addiction. Neuropharmacology 56 [Suppl 1]:18-31.

Koob GF, Le Moal M (2008) Neurobiological mechanisms for opponent motivational processes in addiction. Philos Trans R Soc Lond B Biol Sci 363:3113-3123.

Kreibich AS, Blendy JA (2004) cAMP response element-binding protein is required for stress but not cocaine-induced reinstatement. J Neurosci 24:6686-6692.

Kreibich AS, Briand L, Cleck JN, Ecke L, Rice KC, Blendy JA (2009) Stressinduced potentiation of cocaine reward: a role for CRF R1 and CREB. Neuropsychopharmacology 34:2609-2617.

Krishnan V, Han MH, Graham DL, Berton O, Renthal W, Russo SJ, Laplant Q, Graham A, Lutter M, Lagace DC, Ghose S, Reister R, Tannous P, Green TA, Neve RL, Chakravarty S, Kumar A, Eisch AJ, Self DW, Lee FS, et al. (2007) Molecular adaptations underlying susceptibility and resistance to social defeat in brain reward regions. Cell 131:391-404.

Kuo YM, Liang KC, Chen HH, Cherng CG, Lee HT, Lin Y, Huang AM, Liao RM, Yu L (2007) Cocaine-but not methamphetamine-associated memory requires de novo protein synthesis. Neurobiol Learn Mem 87:93-100.

Kuzmin AV, Semenova S, Gerrits MA, Zvartau EE, Van Ree JM (1997) Kappa-opioid receptor agonist U50,488H modulates cocaine and morphine self-administration in drug-naive rats and mice. Eur J Pharmacol 321:265-271.

Lemberger T, Parkitna JR, Chai M, Schütz G, Engblom D (2008) CREB has a context-dependent role in activity-regulated transcription and maintains neuronal cholesterol homeostasis. FASEB J 22:2872-2879.

Mattson BJ, Bossert JM, Simmons DE, Nozaki N, Nagarkar D, Kreuter JD, Hope BT (2005) Cocaine-induced CREB phosphorylation in nucleus accumbens of cocaine-sensitized rats is enabled by enhanced activation of extracellular signal-related kinase, but not protein kinase A. J Neurochem 95:1481-1494.

McClung CA, Nestler EJ (2003) Regulation of gene expression and cocaine reward by CREB and $\triangle F$ FosB. Nat Neurosci 6:1208-1215.

McPherson CS, Lawrence AJ (2007) The nuclear transcription factor CREB: involvement in addiction, deletion models and looking forward. Curr Neuropharmacol 5:202-212.
Miller CA, Marshall JF (2005) Molecular substrates for retrieval and reconsolidation of cocaine-associated contextual memory. Neuron 47:873884 .

Negus SS, Mello NK, Portoghese PS, Lin CE (1997) Effects of kappa opioids on cocaine self-administration by rhesus monkeys. J Pharmacol Exp Ther 282:44-55.

Nestler EJ (2004) Molecular mechanisms of drug addiction. Neuropharmacology 47 [Suppl 1]:24-32.

Nestler EJ, Malenka RC (2004) The addicted brain. Sci Am 290:78-85.

Neve RL, Howe JR, Hong S, Kalb RG (1997) Introduction of the glutamate receptor subunit 1 into motor neurons in vitro and in vivo using a recombinant herpes simplex virus. Neuroscience 79:435-447.

Newton SS, Thome J, Wallace TL, Shirayama Y, Schlesinger L, Sakai N, Chen J, Neve R, Nestler EJ, Duman RS (2002) Inhibition of cAMP response element-binding protein or dynorphin in the nucleus accumbens produces an antidepressant-like effect. J Neurosci 22:10883-10890.

Paxinos G, Watson GC (1998) The rat brain in stereotaxic coordinates, 4th Ed. New York: Academic.

Pliakas AM, Carlson RR, Neve RL, Konradi C, Nestler EJ, Carlezon WA Jr (2001) Altered responsiveness to cocaine and increased immobility in the forced swim test associated with elevated cAMP response elementbinding protein expression in nucleus accumbens. J Neurosci 21:73977403.

Renthal W, Kumar A, Xiao G, Wilkinson M, Covington HE 3rd, Maze I, Sikder D, Robison AJ, LaPlant Q, Dietz DM, Russo SJ, Vialou V, Chakravarty S, Kodadek TJ, Stack A, Kabbaj M, Nestler EJ (2009) Genome wide analysis of chromatin regulation by cocaine reveals a novel role for sirtuins. Neuron 62:335-348.

Richardson NR, Roberts DC (1996) Progressive ratio schedules in drug selfadministration studies in rats: a method to evaluate reinforcing efficacy. J Neurosci Methods 66:1-11.

Rüedi-Bettschen D, Rowlett JK, Spealman RD, Platt DM (2010) Attenuation of cocaine-induced reinstatement of drug seeking in squirrel monkeys: kappa opioid and serotonergic mechanisms. Psychopharmacology (Berl) 210:169-177.

Sakai N, Thome J, Newton SS, Chen J, Kelz MB, Steffen C, Nestler EJ, Duman RS (2002) Inducible and brain region-specific CREB transgenic mice. Mol Pharmacol 61:1453-1464.

Schenk S, Partridge B, Shippenberg TS (1999) U69593, a kappa-opioid agonist, decreases cocaine self-administration and decreases cocaineproduced drug-seeking. Psychopharmacology 144:339-346.

Shaw-Lutchman TZ, Barrot M, Wallace T, Gilden L, Zachariou V, Impey S, Duman RS, Storm D, Nestler EJ (2002) Regional and cellular mapping of cAMP response element-mediated transcription during naltrexoneprecipitated morphine withdrawal. J Neurosci 22:3663-3672.

Shaw-Lutchman TZ, Impey S, Storm D, Nestler EJ (2003) Regulation of CRE-mediated transcription in mouse brain by amphetamine. Synapse 48:10-17.

Shiflett MW, Mauna JC, Chipman AM, Peet E, Thiels E (2009) Appetitive Pavlovian conditioned stimuli increase CREB phosphorylation in the nucleus accumbens. Neurobiol Learn Mem 92:451-454.

Sun H, Green TA, Theobald DE, Birnbaum SG, Graham DL, Zeeb FD, Nestler EJ, Winstanley CA (2010) Yohimbine increases impulsivity through activation of cAMP response element binding in the orbitofrontal cortex. Biol Psychiatry 67:649-656.

Tropea TF, Kosofsky BE, Rajadhyaksha AM (2008) Enhanced CREB and DARPP-32 phosphorylation in the nucleus accumbens and CREB, ERK, and GluR1 phosphorylation in the dorsal hippocampus is associated with cocaine-conditioned place preference behavior. J Neurochem 106:17801790.

Wallace DL, Han MH, Graham DL, Green TA, Vialou V, Iñiguez SD, Cao JL, Kirk A, Chakravarty S, Kumar A, Krishnan V, Neve RL, Cooper DC, Bolaños CA, Barrot M, McClung CA, Nestler EJ (2009) CREB regulation of nucleus accumbens excitability mediates social isolation-induced behavioral deficits. Nat Neurosci 12:200-209.

Walters CL, Blendy JA (2001) Different requirements for cAMP response element binding protein in positive and negative reinforcing properties of drugs of abuse. J Neurosci 21:9438-9444.

Wee S, Orio L, Ghirmai S, Cashman JR, Koob GF (2009) Inhibition of kappa opioid receptors attenuated increased cocaine intake in rats with extended access to cocaine. Psychopharmacology 205:565-575. 